\title{
论中国的榕树和相关动物的综合研究
}

\author{
李宏庆 ${ }^{1}$ 陈 勇 $^{2}$ 马炜梁 \\ 1 ( 华东师范大学生命科学学院, 上海 200062) \\ 2 ( 宁德师范高等专科学校, 福建宁德 352100)
}

摘要: 榕属 (Ficus) 植物与其传粉昆虫榕小蜂之间有着一对一的专性共生关系, 也与其他相关动物之间存在错综复 杂的生态关系, 已成为生态学领域的热点之一。榕属与榕小蜂亚科的系统分类、物种多样性、榕树雌雄异株的产生 与维持、协同进化、个体生态学等方面的课题值得深入研究。中国生物区系历史悠久、气候带跨幅大、生境多样, 有 榕属植物 98 种 (其中 71 种为雌雄异株榕树), 并具有丰富多样性的动物群落, 能为进行共生生物学研究提供极好 的素材和实验基地。迄今人们对其认识仍十分有限, 可望利用中国的生物、地理资源优势, 在这一领域里进行有规 划的综合研究, 促进榕树与相关动物的研究向纵深发展。

关键词：榕属，榕小蜂，协同进化，生物多样性

中图分类号:Q948.12+2.5 文献标识码 : A 文章编号 : 1005-0094(2002) $02-0219-06$

\section{On synthetic research on fig trees (Moraceae) and related fauna in China}

LI Hong-Qing ${ }^{1}$, CHEN Yong ${ }^{2}$, MA Wei-Liang ${ }^{1}$

1 School of Life Science, East China Normal University , Shanghai , 200062

2 Ningde Junior Teacherśs College, Ningde, Fujian , 352100

\begin{abstract}
The 750 species of Ficus (Moraceae) constitute the most distinctive and widespread genus of tropical plants. There are species-specific mutualisms between fig trees and their pollinating insects ( $A g$ aonidae) and perplexing relationships within the ecosystem. Valuable research results in the areas of the systematics of Ficus and fig wasps, the origin and maintenance of dioecy, biodiversity , co-evolution and ethology are provided by the approaches of systematics, biogeography, ecology, and conservation biology. China's ancient biogeographic realm, its unique geographic traits and the diversity of its fig flora ( 71 dioecious species) make it an ideal location to study these questions. Up to now , we have determined less than 20 species of pollinators (Agaonidae) of the $98 \mathrm{fig} /$ pollinator mutualisms in China , and our knowledge of these fig trees and related animals is still very limited. In utilizing the resourceful advantages of Chinese biota and geography, well-organized programs will advance smoothly and stimulate further research into fig trees and associated animals.
\end{abstract}

Key words : Ficus, fig wasps, co-evolution, biodiversity

全世界榕属 (Ficus) 植物有750 种 (Berg, 1989 ) 榕树与相关动物的研究是十多年来生态学 领域的热点之一,近年又有了更深入广泛的研究报 道 (Weiblen , 2000 ; Cabrita et al. , 2001 ; Patel \& Hossaert-McKey , 2000 ; Kjellberg et al. , 2001 ; Hossaert-McKey \& Bronstein , 2001 ; Song et al. ,2001 ;
李宏庆等,2001; 陈勇,2001; 陈勇等,2001; 杨大荣 等 2000)。中国约有榕属植物 100 种 (中国科学院 中国植物志编委会,1998)，它们是独具特色的热 带、亚热带植物区系的重要成分。迄今人们对中国 榕属植物及相关动物的认识仍十分有限 (马炜梁 等 ,1997)。 


\section{1 榕属植物的特点}

榕属植物有多种生活型, 如落叶或常绿、乔木、 攀缘灌木、丛枝灌木、藤本、附生或半附生（Berg， 1990 )。除了雌花、雄花外, 还有瘻花、中性花和两 性花; 有雌雄同株、雌雄异株及次生雌雄同株等植株 类型。多数榕树种群内树间开花的不同步性与树内 开花的同步性形成强烈对比（Janzen，1979;Berg， $1990)$ 。榕属植物是热带雨林中具有极其重要生态 意义的关键种 (Keystone)（许再富，1994），其结实率 是所有种子植物中最高的, 果实、种子营养价值丰富 (赵庭周等，2001）, 常年向松鼠、蝙蝠、猴、乌、蚂蚁 等提供食物。这些动物与其说是榕树果实和种子的 捕食者, 冊宁说是种子的传播者。在各大陆的热带 森林中，榕属植物的频度、多度、显著度在所有木本 属植物中始终位居前列（Berg，1990），是构成热带 雨林的标志性景观如绞杀、板根、气根、老茎生花等 现象的主要植物类群。榕属植物与它们的传粉昆虫 (榕小蜂亚科 Agaonidae) 之间有着一对一的专性共 生关系，从白严纪以来历经 1 亿多年的协同进化，其 相互依赖已经达到了不能互缺的程度 (Galil et al. 1973 ) 比其他动植物间的共生关系 (如 :蚁 - 金合 欢 (Acacia spp.)、长舌花蜂 ( euglossine bees) - 兰 花、蛾 - 丝兰 (Yacca sp. )、蚁 - 附生植物、蚁 - 真 菌 ) 更为复杂和高级。不论环境中有几种榕属植物 (同时就有几种共生小蜂), 也不管其有性生殖的时 期如何,在同一生境中的榕属植物种间不存在争夺 传粉者的竞争 (Janzen, 1979)。榕属植物常出现在 村边田头，一株树上可以飞出上万乃至几百万只榕 小蜂 (pollinators) 数量如此庞大的小昆虫却从来不 袭扰居民，从来不侵害庄稼。

此外, 榕属植物与人类关系密切: 菩提树 $(F$. religiosa)、高山榕 ( F. altissima) 成为佛教和少数民 族的神树; 一些地方已建立起上万亩的无花果 $(F$. carica) 果园;一些榕树的果、叶被作为野生水果和蔬 菜; 一些榕树的不同部位可入药;聚果榕 ( F. racem$o s a)$ 和斜叶榕 ( F. gibbosa) 可以放养紫胶虫 (Kerria lacca) 生产紫胶; 爱玉子( $F$. pumila var. awkeotsang ) 已作为低热量半饮料的现代食品开发生产;薜 荔 (F. pumila $)$ 隐头果内的榕小蜂富含赖氨酸和蛋 氨酸,有开发前景(陈友铃等,1999) ; 在世界许多地 方, 榕树 ( F. microcarpa $)$ 等众多榕属植物早已成为
园林绿化的主要树种。

\section{2 在中国开展此项研究的特殊意义}

榕树及其传粉者之间互惠共生专一性方面的一 些主要问题可以期望在中国的研究中找到答案, 这 是因为：

中国植物区系的古老性:华夏植物区系富含古 老的被子植物类群。榕属植物化石 Ficophyllum 与 被子植物的最早化石同时发现于白严纪, 它经历了 一条独特的演化路线，从现今种类的解剖、形态和数 量上看，亚洲和澳大利亚生物地理区的榕树多样性 远比非洲和新热带区强, 其中尤以亚洲为甚 (Berg, 1989 ; Patel et al. , 1993 )。在这一有着古老历史背 景的区域研究榕树和传粉昆虫的比较生物学, 对于 探讨被子植物的起源和演化, 植物与动物的协同进 化是极具学术价值的。

中国独特的地理位置:中国气候带的跨幅大,生 境多样,为热带植物榕树的多样性辐射演化 (diverse radiation) 提供了多种条件，因而与一些热带国家相 比, 当今在中国研究协同进化的机理、雌雄异株的演 化及个体生态学问题, 具备更全面、更优越的地理条 件。

\section{3 几个研究方面}

3.1 系统分类方面的研究

有关榕属植物的分类各省区均已作了研究, 云 南有 64 种 27 变种 (中国科学院昆明植物研究所, 1984 ) 、海南有 33 种 6 变种 (中国科学院华南植物 研究所 ,1965)、香港有 27 种（Hill，1971），廖日京研 究了台湾的榕树共有 45 种 23 变种, 其中 27 种 10 变种为当地自生种 (廖日京, 1991)。《中国植物志》 (中国科学院中国植物志编委会,1998) 中记载中国 共有榕树 98 种，其中雌雄异株种类为 71 种，中国特 有种 17 种 15 变种,主要分布在中国的种有 9 种。 小蜂 (wasps) 方面, 台湾张吉清 ${ }^{\mathbb{1}}$ 对榕树 (F. microcarpa) 上的 9 种小蜂进行了分类研究, Hill (1967) 发 现了香港 4 个榕小蜂新种, 香港共有 70 种小蜂 《中 国经济昆虫志》上仅记载了 1 种一一对叶榕榕小蜂 (Ceratosolen solmsi marchali )（廖定喜等,1987)。至

(1)张吉清, 1983. 台湾榕树果实蜂之研究. 台湾东海大学生物学研 究所硕士学位论文. 
今，我国已知的共生榕小蜂不足 20 种 (杨大荣等, 1999)。国际上对榕树与榕小蜂进行了合作研究, 榕属 18 组中多数组都有特定的传粉者与之对应 (Wiebes，1979，1994），而榕小蜂亚科的分类系统 与其宿主榕树的分类系统之间却没有绝对的对应关 系,Wiebes (1994) 呼吁:急需进行精确的系统发育 分析才有可能探明二者的分类单元不相匹配的原 因。

中国的榕树和榕小蜂的分类工作基本停留在经 典的形态分类上。如果参照它们的共生伙伴，从系 统发育的角度进行研究, 有可能产生受到国际关注 的新突破。因为这样的分类不再局限在比较形态学 的范畴, 它采用包括生理学的、生态学的、动物行为 学的、分子生物学的指标, 研究成果也不仅是分门别 类的分类，而是对动植物间协同进化的历史和途径 的探讨。

为了这一研究, 需要昆虫学家和榕属分类学家 进行种类鉴定, 要有合适的样地或植物园以便定期 采样记录物候与生活史, 观察传粉生态, 分辨哪一种 小蜂是专一的共生者，哪些小蜂只是榕树的寄生者， 哪些小蜂又是专食榕小蜂幼虫的寄生蜂, 并进行解 剖生理学的和分子生物学的研究。

\section{2 与榕树相关的其他生物的生态学研究}

一株榕树上通常可以聚集 10 种或更多种喜隐 头花序的昆虫，它们是 榕树一传粉者” 互惠共生体 系的寄生者，它们在榕属祖先引起花序的关闭的选 择上可能起了重要的作用，因此也间接地促进了 榕树一传粉者”的协同进化。它们或许有利于雌 雄异株的分化，或许还在继续对当代榕属区系的多 样性起作用。

多类有机体与榕树有着密切的关系, 如线虫 (Nematoda)、菌类 (Fungi)、螨类 (mites)、同翅目 (Homoptera) 、双翅目 (Diptera) 和鞘翅目 (Goleoptera) 昆虫等，它们与榕树之间的生态关系是很 值得研究的。例如: 蚂蚁是传粉小蜂的重要捕食者 和榕树种子的传播者，蚂蚁的捕食也减少了非传粉 昆虫的寄生率, 而寄生的非传粉昆虫对蚂蚁的吸引 也间接地有益于 榕树一榕小蜂” 的共生体系。西 双版纳热带雨林榕树动物群落中蜱螨类、昆虫类、伪 螨类、蜘蛛类、唇足类、鸟类、兽类等大都围绕着榕树 有规律地生存和发展 (杨大荣等, 1997)。危害或取 食木瓜榕 (Ficus auriculata) 和对叶榕 (Ficus hispida)
的昆虫种类繁多 (苏绍菊, 2001)。隔担子菌 (Septobasidium sp.) 引起榕树 (F. microcarpa) 的烂皮病 （杨佐忠等，2000）;灰白虫蛾（Ocinara varians）在福 建福州是榕树的一种重要害虫(罗佳, 梁进新, 1997 )。榕树对食榕果脊椎动物传播种子的适应能 力也是尚待研究的课题之一。

\section{3 植物和昆虫协同进化的研究}

750 种左右的 榕树一传粉者”体系内种的专一 性使得榕树成为协同进化研究的极丰富的实验材 料, 因而成为国际上的一个研究热点。榕属各组之 间的进化关系与传粉小蜂各属间的进化关系有相当 的吻合 (Wiebes, 1994)。但还有未确定的疑点, 在 高一级的分类水平上它们的系统发育关系还没有弄 清, 宿主榕树所表现的适应特征能否用于榕小蜂的 形态分类尚有争议。榕小蜂的一些形态特征的相似 性也许是趋同进化造成的, 而不是因为它们拥有共 同的祖先。同样的问题也存在于榕树的分类中, 因 此需要运用与互惠共生无关的一些特征来分析。还 可能由于宿主转移造成这 2 个分类系统的无法匹 配, 可以通过实验人为地干扰其专一性进行研究。

传粉小蜂在同一生境中能否准确地选择宿主, 取决于其对宿主花序分泌物的辨别, 研究并鉴定这 些挥发性吸引物的成分有可能查清这类物质在物种 形成、协同进化、宿主转移等过程中的作用 ( Hossaert-McKey et al. , 1994)。

雌雄异株的榕树必须有榕小蜂进入雌花序传粉 才能结出种子, 但是凡进入雌花序的榕小蜂皆不能 产卵完成自身的繁殖;而雄瑤株的大量光合作用产 物皆为共生小蜂所消耗, 植株上却不能结出一粒种 子。在进化过程中, 凡不利于自身繁殖的特征常常 是无后的, 自然选择不予保留, 那么动植物双方又是 以怎样的对策来解决这一矛盾，从而维持这一共生 体系的呢? Grafen \& Godfray (1991) 提出植物是靠模 拟、靠 欺骗”引诱榕小蜂进入雌花序的;Song et al. (2001) 分析了 F. hispida 雌花期和间花期榕果的挥 发性引诱物, 发现雌雄花序在雌花期释放的挥发性 引诱物相似，但不同时期榕果的挥发性成分则有明 显差别, 并证实只有雌花期榕果的挥发性成分才能 吸引传粉小蜂 (Song et al. , 2001)。它们的群体选 择效应, 它们的形态学、生理学和生态学的基础是极 值得研究的课题。马炜梁和吴翔 (1989) 、李宏庆等 $(1999,2000,2001)$ 、陈勇等 $(2001)$ 、杨大荣等 
(2000)、Song et al. (2001) 为在中国开展榕一蜂共 生关系研究作了开创性的尝试。

短命的榕小蜂出飞后如果找不到受粉期的花序 就会导致雄性失败 (male failure) ;反之, 受粉期的植 株若无榕小蜂拜访则导致全失败 (total failure) ,榕 小蜂将灭绝，榕树也无结实。在这里，榕树的濒危种 群大小 ( critical population size, CPS) 是维持榕小蜂 种群的最低要求。与热带的非季节性环境相比, 在 季节性气候条件下, 榕树与榕小蜂在一年中某个特 定时期形成开花、出蜂的高潮。而在开花的低潮中， 由于维持传粉者种群的需要, CPS 值增大。季节性 气候对榕树与榕小蜂的极度影响会导致传粉者种群 的灭绝以及随之而来的榕树的灭绝。种群数量高于 CPS 值时也会偶然发生雄性失败或全失败, 这时季 节性气候将增加这种失败的可能性。Bronstein (1989) 认为榕树和传粉者要在强烈的季节性环境 条件下生存下来, 需具备两个特性 : 1) 榕小蜂进化 出更长的寿命或更强的飞行能力;2) 隐头花序发育 时间的可塑性增大, 使榕小蜂在严酷的季节里可以 留在花序中更长的时间。此外, 可受粉阶段的延长 将大大减少维持传粉者种群所必须的榕树数量。以 上种种假设都需要实验验证。中国与热带国家相比 具有广大的季节性气候地区, 在不同环境下进行比 较研究, 其成果将会是十分引人注目的。李宏庆等 (1999) 证实,分布于中国福建的薜荔 (F. pumila) 雄 掼花序的发育时间可达半年以上。陈勇等 (1996) 对薜荔榕小蜂出飞节律与光因子的关系进行了探 讨, 发现光线是榕小蜂建立出飞节律的决定性因素 之一。

预报人类活动对 榕树一传粉者”互惠共生关 系稳定性的影响需要多方面的信息, 如 :1) 榕树种 群的 CPS 值是多少? 2) 榕树种群的密度和大小是 多少? 3 ) 森林保护会导致榕树种群增大还是反而 导致种群变小? 就保护生物学来说, 研究如何使人 类自身的活动有利于这种互惠共生关系的稳固, 使 一地的榕树数量保持在 CPS 值之上, 以保护依赖这 些关键物种生存的众多昆虫、鸟类和哺乳动物, 具有 深远的意义。在中国研究榕一蜂共生体系受威胁的 程度, 对全球生物多样性保护是一个重要贡献。

\section{4 雌雄异株的榕树的进化和维持的研究}

Kjellberg \& Maurice (1989) 指出: 强烈的季节性 气候使得榕树种子和榕小蜂的生产在一年中的不同
时间里形成高峰, 榕树的雄性功能 (male function) 和雌性功能 (female function) 得到加强, 榕树通过花 柱长度的改变导致形成雌株和雄株两类表现型, 因 而他预言有三个方面的变化: : ) 雌雄异株的榕树拥 有这样一种物候 雄株开花在同一时期形成一个高 峰, 并传递花粉到同步开花的雌株, 而在一年中的其 他时间里雄株又在榕树内以少量的开花抚养传粉 者 2) 这里的榕树与非季节性环境 (热带) 相比更高 产 3 ) 这里的雌雄同株种类在树内或树间的花序会 有单性化的倾向。这些预言有的已被证实,有的尚 待研究。我国大面积的季节性环境和丰富的榕树种 类为研究雌雄异株的进化提供了丰富的材料和极好 的地理条件。进一步的研究又表明了榕属中一个雌 雄异株的组 Sycocarpus 是在非季节性变化的环境中 发生和维持的, 因此, 雌雄异株的榕树至少存在两条 进化路线而且分布区有重迭, 雌性和雄性植株在隐 头花序的形态、发育时间和个体物候方面都是有差 异的,它们所受的选择压力也是不同的。比较物候 学研究将能揭示雌雄异株在不同气候条件下是如何 体现其优越性的, 它们在不同的谱系中是如何进化 的, 揭示它们最终的生物地理分布是怎样形成的。 印度已建立了此项研究的专项基金 (Patel et al. , 1993 ) 然而在中国有关研究尚未起步。

作用于“雌雄异株榕树一传粉者”体系的破坏 性因素会导致回复进化, 成为次生雌雄同株。同时 研究雌雄异株及雌雄同株榕树的发生发展历史, 有 可能提出对次生雌雄同株现象的解释。

\section{5 “榕树一传粉者” 相互关系的个体生态学}

以上各个研究论题中, 贯穿着许多个体生态学 的问题。例如 :1) Kjellberg et al. (2001) 对 88 个 Ficus种及其传粉者的观察表明, 通过榕树花药与胚 珠的比率或榕小蜂是否出现基节栉 (coxal combs), 能预测榕小蜂的传粉模式是主动的还是被动的。榕 小蜂的主动传粉行为与蜜蜂的被动传粉有根本的差 别。那么, 榕小蜂是怎样从被动传粉体系演化成主 动传粉的, 主动传粉对榕小蜂有何优越性? 有一种 论点认为掼花的胚珠得到传粉受精对于传粉小蜂幼 虫的成功发育是必须的, 那么主动传粉的进化在植 物进化上有何反应? 传粉效率的提高是否会导致主 动传粉的榕树相应地减少产生花粉方面的 投资”？ Kjellberg et al. (2001) 的工作提供了有益的指南 2) 在雌雄同株榕树上的榕小蜂的行为在榕树产生种 
子、榕小蜂产生后代的相对数量上所起的作用是什 么? ? ) 雌蜂怎样调节其后代的性比? 雌蜂能否估计 出自身后代以及同一果序内其他雌蜂后代的性比并 相应地改变、调节其后代性比?4) 维持传粉者一宿 主专一性的最可能的机制是什么? 花序的挥发性吸 引物的研究会引出榕小蜂对宿主化学所作反应的许 多有趣的神经生物学问题 5) 雌雄异株榕树的传粉 系统怎样维持? 个体生态学在解释这些系统的进化 稳定性方面能作出重要的贡献并可能阐明雌雄异株 体系是怎样回复到雌雄同株状态的。

综上所述 “，榕树一传粉者” 的相互作用给分类 学、生物地理学、生态学和系统与进化学提出了重要 而有趣的课题, 中国悠久的生物历史背景, 独特的地 理条件，多样的 榕树一传粉者” 资源提供了进行这 方面研究的极好的素材和实验基地，为运用进化生 物学理论研究当代亟待解决的物种保护问题提供了 大量的机会。利用中国的生物、地理资源优势，在这 一领域里进行有规划的综合研究，必将促进榕树与 相关动物的研究向纵深发展。

\section{参考文献}

陈 勇, 2001. 爱玉子及其传粉昆虫的研究. 宁德师专学报, 13(3) : $204 \sim 207$

陈勇, 李宏庆, 马炜梁, 2001。雀榕及其传粉昆虫传粉生态研 究. 生态学报, 21(10): 1569 1574

陈 勇, 马炜梁, 罗光坦, 1996. 薜荔榕小蜂出飞节律与光因子 的关系. 生态学报, 16(2): 160 166

陈友铃, 吴文珊, 方玉霖, 江剑平, 1999. 薜荔榕小蜂的营养 成分研究. 生物学杂志, 16(4) : 13 14

李宏庆, 陈勇, 马炜梁, 2001. 天仙果的繁殖生物学研究. 生 态学报, 21(8): 1385 1387

李宏庆, 陈勇, 鲁心安, 马炜梁, 1999. 薜荔传粉的代价. 生 态学杂志, 18(3): $66 \sim 69$

李宏庆, 陈勇, 鲁心安, 马炜梁, 2000. 薜荔榕小蜂繁殖的代 价. 昆虫知识, 37(5): 302 303

廖定喜, 李学骝, 庞雄飞, 陈泰鲁, 1987. 中国经济昆虫志, 第 34 册, 膜翅目, 小蜂总科 (一). 北京: 科学出版社, $44 \sim$ 45

廖日京, 1991. 台湾桑科植物之学名订正. 台湾省台北市国 立台湾大学农学院森林学系出版, 17 184

罗佳, 梁进新, 1997. 灰白虫蛾生物学特性的研究. 华东昆 虫学报, 6(1):31 34

马炜梁, 吴翔, 1989. 薜荔榕小蜂与薜荔的共生关系. 生态 学报, 9(1): 9 14

马炜梁, 陈勇, 李宏庆, 1997. 榕树及其传粉者研究综述. 生
态学报, 17(2) : 209 215

苏绍菊, 2001. 木瓜榕和对叶榕上昆虫群落结构. 思茅师范 高等专科学校学报, 17(3): 90 95

许再富, 1994. 榕树一一滇南热带雨林生态系统中的一类关 键植物. 生物多样性, 2(1):21 23

杨大荣, 李朝达, 杨 兵, 1997. 西双版纳热带雨林中榕树动物 群落结构与多样性研究. 动物学研究, 18(2) : 189 196 杨大荣, 王瑞武, 宋启示, 张光明, 赵庭周, 2000. 西双版纳热 带雨林聚果榕小蜂季节性变化规律. 林业科学研究, 13 (5) : $477 \sim 484$

杨大荣, 李朝达, 韩灯保, 姚瑞英, 1999. 热带雨林片断化对 榕小蜂和榕树物种的影响. 动物学研究, 20(2): 126 130

杨佐忠, 朱天辉, 邱德勋, 牟代全, 刘度南, 吴人柯, 刘玉梅, 何 跃兵, 2000. 榕树烂皮病病原及流行原因初步研究. 四 川林业科技, 21(3): 22 24

赵庭周, 杨大荣, 许继宏, 2001. 榕树在西双版纳热带雨林中 的地位和综合利用价值. 林业科学研究, 14(4): 441 445

中国科学院华南植物研究所, 1965. 海南植物志. 北京: 科 学出版社, 2: $384 \sim 400$

中国科学院昆明植物研究所, 1984. 云南植物名录. 云南人 民出版社, 699 711

中国科学院中国植物志编委会, 1998. 中国植物志. 北京: 科 学出版社

Berg C C, 1989. Classification and distribution of Ficus. Experientia, 45: $605 \sim 611$

Berg C C, 1990. Reproduction and evolution in Ficus (Moraceae) : traits connected with the adequate rearing of pollinators. Memoirs of the New York Botanical Garden, 55:169 185

Bronstein J L, 1989. A mutualism at the edge of its range. Experientia, 45: $622 \sim 637$

Cabrita L F, U Aksoy, S Hepaksoy and J M Leitao, 2001. Suitability of isozyme, RAPD and AFLP markers to assess genetic differences and relatedness among fig (Ficus carica L.) clones. Scientia Horticulturae, 87: 261 273

Galil J, M Zeroni and D Bar Shalom, 1973. Carbon dioxide and ethylene effects in coordination between the pollinator Blastophaga quadraticeps and the syconium in Ficus religiosa. The New Phytologist, 72: $1113 \sim 1127$

Grafen A and H C J Godfray, 1991. Vicarious selection explains some paradoxes in dioecious fig-pollinator systems. Proceedings of the Royal Society of London, Series B: Biological Sciences, 245: $73 \sim 76$

Hill D S, 1967. Fig-wasps (Chalcidoidea) of Hong Kong, I. Agaonidae. Zoologische Verhamdelingen, 89: $3 \sim 55$

Hill D S, 1971. Wasps and figs. New Scientist and Science Journal, 15: $144 \sim 146$ 
Hossaert-McKey M and J L Bronstein, 2001. Self-pollination and its costs in a monoecious fig (Ficus aurea, Moraceae) in a highly seasonal subtropical environment. American Journal of Botany, 88(4): $685 \sim 692$

Hossaert-McKey M, M Gibernau and J E Frey, 1994. Chemosensory attraction of fig wasps to substances produced by receptive figs. Entomologia Experimentalis et Applicata, 70: $185 \sim 191$

Janzen D H, 1979. How to be a fig. Annual Review of Ecology and Systematics, 10:13 51

Kjellberg F, E Jousselin, J L Bronstein, A Patel, J Yokoyama and J Y Rasplus, 2001. Pollination mode in fig wasps: the predictive power of correlated traits. Proceedings of the Royal Society of London, Series B: Biological Sciences, 268 (1472) : $1113 \sim 1121$

Kjellberg F and S Maurice, 1989. Seasonality in the reproductive phenology of Ficus: Its evolution and consequences. Experientia, 45: $653 \sim 660$

Patel A and M Hossaert-McKey, 2000. Components of repro- ductive success in two dioecious fig species, Ficus exasperata and Ficus hispida. Ecology, 81 (10): 2850 2866

Patel A, M Hossaert-McKey and D McKey, 1993. Ficus-pollinator research in India: past, present and future. Current Science, $65(3): 243 \sim 253$

Song Q, D Yang, G Zhang and C Yang, 2001. Volatiles from Ficus hispida and their attractiveness to fig wasps. Journal of Chemical Ecology, 27(10): $1929 \sim 1942$

Weiblen G D, 2000. Phylogenetic relationships of functionally dioecious Ficus (Moraceae) based on ribosomal DNA sequences and morphology. American Journal of Botany, 87 (9) : $1342 \sim 1357$

Wiebes J T, 1979. Figs and their insect. Annual Review of $E$ cology and Systematics, 10: $1 \sim 12$

Wiebes J T, 1994. Agaonidae (Hymenoptera Chalcidoidea) and Ficus (Moraceae): fig wasps and their figs, XIV (conclusion-Old World). Proceedings of the Koninklijke Nederlandse Akademie van Wetenschappen, 97(4) : $491 \sim 495$ 